\title{
The Standard Molar Enthalpies of Formation of Nano-ZnO Particles with Different Morphologies
}

\author{
Ya Li and Xinmin Wu \\ College of Chemical Engineering, Beijing Institute of Petro-Chemical Technology, Beijing 102617, China \\ Correspondence should be addressed to Xinmin Wu; wuxinmin@bipt.edu.cn
}

Received 17 November 2014; Accepted 29 December 2014

Academic Editor: Yoke K. Yap

Copyright (C) $2015 \mathrm{Y}$. Li and X. Wu. This is an open access article distributed under the Creative Commons Attribution License, which permits unrestricted use, distribution, and reproduction in any medium, provided the original work is properly cited.

\begin{abstract}
The thermodynamic properties of nano- $\mathrm{ZnO}$ particles with different morphologies were studied. First, based on the measurements of XRD and SEM, the morphologies of the five nano-ZnO products were determined as sheet, block, sieve, column, and rod, and their particle size was about $40 \mathrm{~nm}$. Then, based on a designed thermodynamic cycle, the standard molar enthalpies of formation $\left(\Delta_{\mathrm{f}} H_{\mathrm{m}}{ }^{\ominus}\right)$ of the nano-ZnO particles were determined by the RD496-2000 microcalorimeter, and they are $\Delta_{\mathrm{f}} H_{\mathrm{m}}{ }^{\ominus}($ sheet $)$ $=(-337.43 \pm 0.47) \mathrm{kJ} \cdot \mathrm{mol}^{-1}, \Delta_{\mathrm{f}} H_{\mathrm{m}}{ }^{\ominus}($ block $)=(-336.57 \pm 0.43) \mathrm{kJ} \cdot \mathrm{mol}^{-1}, \Delta_{\mathrm{f}} H_{\mathrm{m}}{ }^{\ominus}($ sieve $)=(-337.04 \pm 0.57) \mathrm{kJ} \cdot \mathrm{mol}^{-1}, \Delta_{\mathrm{f}} H_{\mathrm{m}}{ }^{\ominus}(\mathrm{column})$ $=(-343.56 \pm 0.39) \mathrm{kJ} \cdot \mathrm{mol}^{-1}$, and $\Delta_{\mathrm{f}} H_{\mathrm{m}}{ }^{\ominus}(\mathrm{rod})=(-341.43 \pm 0.41) \mathrm{kJ} \cdot \mathrm{mol}^{-1}$. The results show that the bigger difference of the morphologies of nano- $\mathrm{ZnO}$, the bigger difference of the standard molar enthalpies of formation.
\end{abstract}

\section{Introduction}

Along with the development of nanotechnology, nano- $\mathrm{ZnO}$ becomes an important new species of material in the nanotechnology field [1-3]. Nano-ZnO is a kind of particles whose size is among $1 \sim 100 \mathrm{~nm}$. Compared with conventional $\mathrm{ZnO}$, nano- $\mathrm{ZnO}$ shows many special properties, such as surface effect and size effect. Because of the small size and large specific surface area, nano- $\mathrm{ZnO}$ exhibits unique properties of light, electricity, heat, and magnetic susceptibility. So it is widely used in many fields, such as ultraviolet absorption materials, piezoelectric materials, magnetic materials, pressure sensitive materials, and medicine [4-6]. It has many morphologies, such as rod, sheet, and needle ones. In present work, the preparation of nano- $\mathrm{ZnO}$ with different morphologies has been studied. It is the base to research the different functions of nano- $\mathrm{ZnO}$ with different morphologies in different fields. The thermodynamic properties are inherent properties of nano material. To find out the change rule of the thermodynamic properties of nano- $\mathrm{ZnO}$ with different morphologies and different sizes is helpful for its application in different fields $[7,8]$. The "word" nanothermodynamics appeared formally in 2000 [9]. Then Giebultowicz classified nanothermodynamics to thermodynamics [10]. He thought nanothermodynamics is a small-system thermodynamics, which created a new branch of thermodynamics. In 2001, Hill published a series of papers about nanothermodynamics in Nano Letters [11-13]. The prospects of nanothermodynamics and the contribution of it to the nanosystem were described in those papers. In 2010, a report about the entropy and enthalpy change of nanoparticle with different sizes was published [14]. But the study on the thermodynamic properties of nano- $\mathrm{ZnO}$ with different morphologies is absent.

In this work, we determined the standard molar enthalpies of solution of nano- $\mathrm{ZnO}$ particles with five different morphologies by RD496-2000 microcalorimeter and calculated the standard molar enthalpies of the nano- $\mathrm{ZnO}$ particles.

\section{Experimental}

2.1. Reagents and Instruments. Reagents: zinc oxide $(\mathrm{ZnO})$ nanoparticles (J\&K Scientific Ltd.), potassium bisulfate (AR, Beijing Jingqiu Chemical Co., Ltd.), potassium sulfate (AR, Beijing Beihua Fine Chemicals Co., Ltd.), potassium chloride (AR, Beijing Chemical Works), and zinc sulfate heptahydrate (AR, Beijing Jingqiu Chemical Co., Ltd.).

Instruments: microcalorimeter (RD496-2000, Mianyang Zhongwu Thermal Analysis Instruments Co., Ltd.), X-ray 
TABLE 1: The enthalpy of solution of $\mathrm{KCl}$ in water at $298.15 \mathrm{~K}$.

\begin{tabular}{lccccc}
\hline Reaction system & Number & $m_{\mathrm{KCl}}(\mathrm{g})$ & $V_{\mathrm{H}_{2} \mathrm{O}}(\mathrm{mL})$ & $Q_{1}(\mathrm{~mJ})$ & $\Delta_{\mathrm{r}} H_{\mathrm{ml}}{ }^{\ominus}\left(\mathrm{kJ} \cdot \mathrm{mol}^{-1}\right)$ \\
\hline & 1 & 0.0112 & 3.0 & 2640.34 & 17.56 \\
\\
$\mathrm{KCl} \rightarrow \mathrm{H}_{2} \mathrm{O}$ & 2 & 0.0112 & 3.0 & 2643.35 & 17.58 \\
& 3 & 0.0112 & 3.0 & 2642.60 & 17.58 \\
& 4 & 0.0112 & 3.0 & 2639.89 & 17.56 \\
& 5 & 0.0112 & 3.0 & 2641.10 & 17.57 \\
\hline Average value & 6 & 0.0112 & 3.0 & 2640.80 & 2641.35 \\
\hline
\end{tabular}

diffractometer (Beijing Purkinje General Instrument Co., Ltd.), and field emission scanning electron microscope (FESEM, JEOL JSM-6700F, USA).

2.2. Characterization of Nano- $\mathrm{ZnO}$. XRD and SEM analyses were done to determine the particle size and morphology of nano- $\mathrm{ZnO}$ products.

2.3. Determination of Standard Molar Enthalpy. The determination of enthalpy of formation was carried out with the RD496-2000 microcalorimeter [15]. To verify the reliability of the microcalorimeter, the molar enthalpy of solution of $\mathrm{KCl}$ in water was measured at $298.15 \mathrm{~K}$, and the experimental data were shown in Table 1 . The calculated molar enthalpy of solution of $\mathrm{KCl}$ was determined to be $17.57 \pm 0.02 \mathrm{~kJ} \cdot \mathrm{mol}^{-1}$, which was within $\pm 0.5 \%$ of literature values $\left(17.56 \pm 0.21 \mathrm{~kJ} \cdot \mathrm{mol}^{-1}\right)$ [16].

The standard enthalpies of formation of nano- $\mathrm{ZnO}$ particles were determined according to a designed chemical cycle shown in Figure 1.

In the experiment of calorimetry, $15 \mathrm{~mL}$ steel reservoir with two separable glass sleeves in it is used as sample cells, and the solid and liquid substances were put into the glass sleeves, respectively. Then the cells were put into calorimeter chamber at $298.15 \mathrm{~K}$; when the baseline kept going steadily (the fluctuation is less than $\pm 0.00001 \mathrm{mV}$ ) the firing pin was triggered to break the glass sleeve and to make the sample mix with the solution. Then the chamber was kept to be at $298.15 \mathrm{~K}$ until the thermodynamic curve kept going parallel to the baseline with very small fluctuation which shows the completion of reaction. In this experiment, the solids were products $\left(0.0141 \mathrm{~g} \mathrm{ZnSO}_{4} \cdot 7 \mathrm{H}_{2} \mathrm{O}\right.$ and $\left.0.0086 \mathrm{~g} \mathrm{~K}_{2} \mathrm{SO}_{4}\right)$ and reactants $\left(0.0040 \mathrm{~g} \mathrm{ZnO}\right.$ and $0.0134 \mathrm{~g} \mathrm{KHSO}_{4}$ ) (there were 5 kinds of reactant systems by choosing different morphologies of nano- $\mathrm{ZnO}$ ) showed in Figure 1. The liquid was $0.3000 \mathrm{~g} \mathrm{HCl}$ solution $\left(0.26 \mathrm{~mol} \cdot \mathrm{L}^{-1}\right)$. The products and reactants were mixed with the $\mathrm{HCl}$ solution separately. Then the heat of the reaction $\left(Q_{1}\right.$ and $\left.Q_{2}\right)$ in the process was determined.

\section{Result Analysis and Discussion}

3.1. Particle Size and Morphology of Nano-ZnO. The XRD and SEM results of 5 kinds of nano-ZnO particles with different morphologies were shown in Figures 2 and 3. The sharp XRD peaks suggest that the products are highly crystallized and the morphology of each nanoparticle is uniform, and the

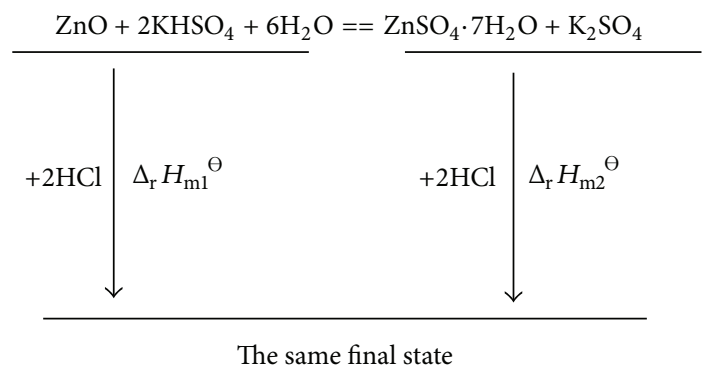

Figure 1: Designed thermochemical cycle of $\mathrm{ZnO}$ reaction system.

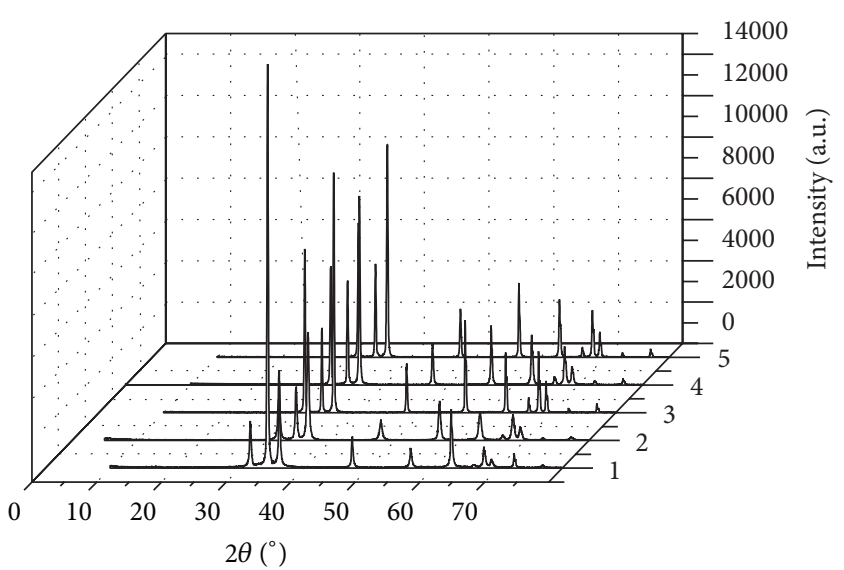

FIGURE 2: XRD spectra of 5 nano- $\mathrm{ZnO}$ particles with different morphologies (the serial numbers 1 5 were denoted by the ones of sheet, sieve, block, column, and rod morphology).

morphologies of the nano- $\mathrm{ZnO}$ can be seen clearly in the SEM pictures.

3.2. Standard Molar Enthalpy of Formation of Nano-ZnO. Standard molar enthalpy of formation of nano- $\mathrm{ZnO}$ can be obtained according to the designed thermodynamic cycle shown in Figure 1 and Hess law, and the detailed calculation was performed as formula (1). The experimental and calculated data were shown in Tables 2, 3, and 4

$$
\begin{aligned}
\Delta_{\mathrm{f}} H_{\mathrm{m}}{ }^{\ominus}(\mathrm{ZnO})= & \Delta_{\mathrm{f}} H_{\mathrm{m}}{ }^{\ominus}\left(\mathrm{K}_{2} \mathrm{SO}_{4}\right) \\
& +\Delta_{\mathrm{f}} \mathrm{H}_{\mathrm{m}}{ }^{\ominus}\left(\mathrm{ZnSO}_{4} \cdot 7 \mathrm{H}_{2} \mathrm{O}\right)
\end{aligned}
$$




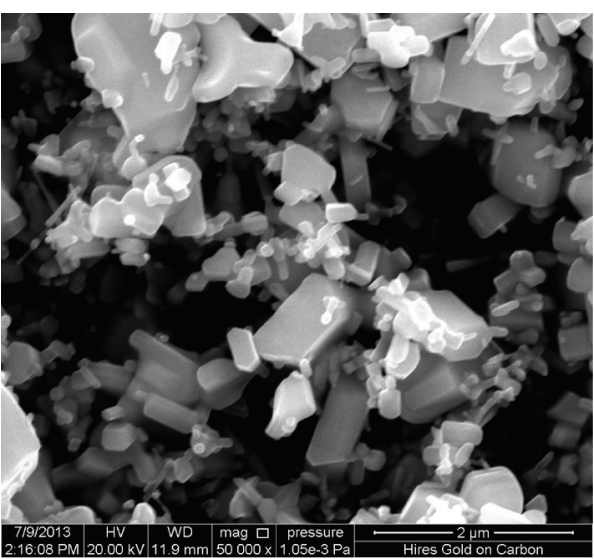

(a) Sheet

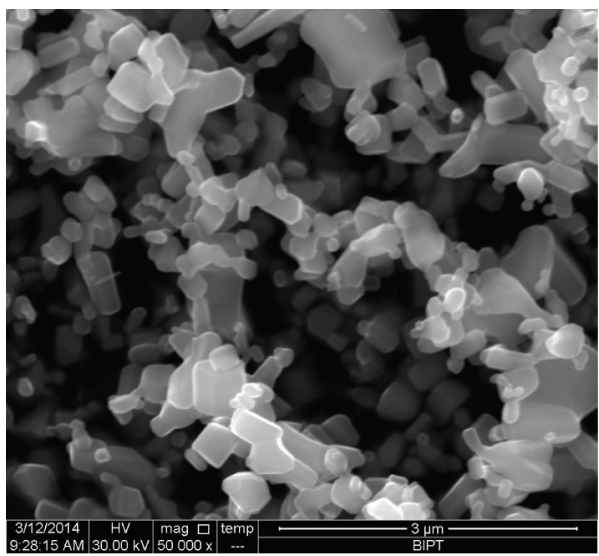

(c) Block

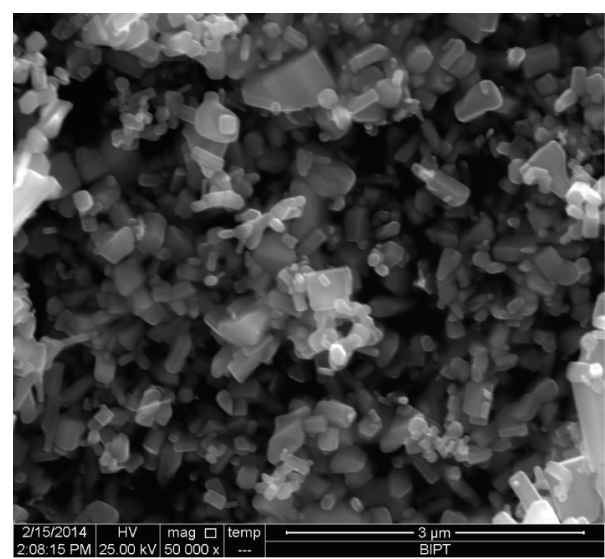

(b) Sieve

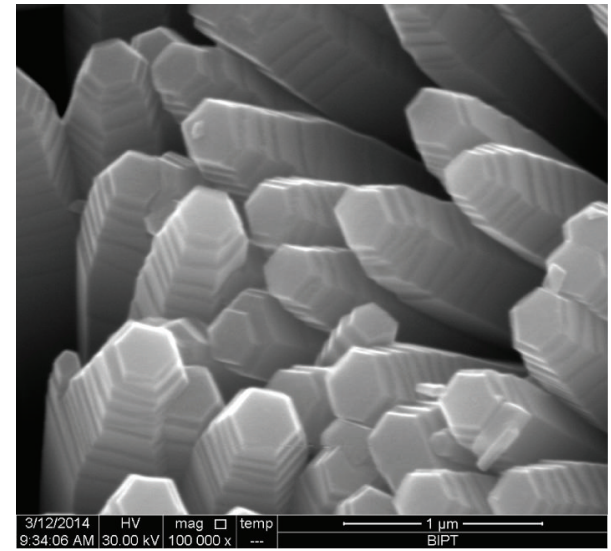

(d) Column

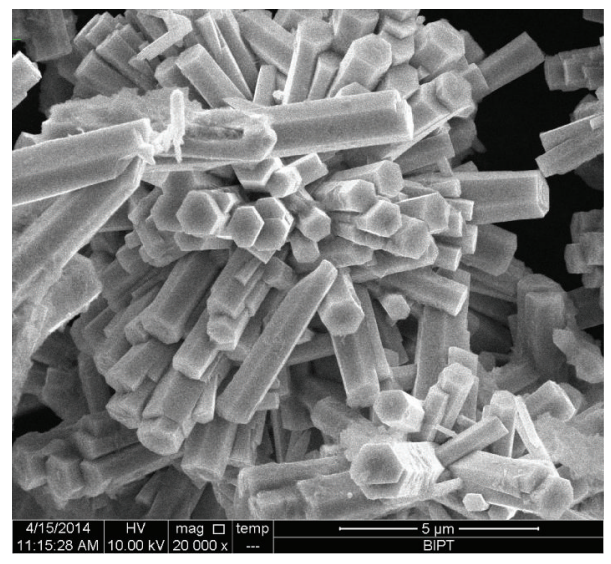

(e) Rod

FIgURE 3: SEM pictures of 5 nano-ZnO particles.

$$
\begin{aligned}
& +\Delta_{\mathrm{r}} H_{\mathrm{m} 2}{ }^{\ominus}-\Delta_{\mathrm{r}} H_{\mathrm{m} 1}{ }^{\ominus} \\
& -6 \Delta_{\mathrm{f}} H_{\mathrm{m}}{ }^{\ominus}\left(\mathrm{H}_{2} \mathrm{O}\right)-2 \Delta_{\mathrm{f}} H_{\mathrm{m}}{ }^{\ominus}\left(\mathrm{KHSO}_{4}\right) \\
= & (-1414) \mathrm{kJ} \cdot \mathrm{mol}^{-1}+(-3077.75) \mathrm{kJ} \cdot \mathrm{mol}^{-1} \\
& -6 \times(-285.83 \pm 0.04) \mathrm{kJ} \cdot \mathrm{mol}^{-1} \\
& -2 \times(-285.83 \pm 0.04) \mathrm{kJ} \cdot \mathrm{mol}^{-1}
\end{aligned}
$$

$$
\begin{gathered}
+\Delta_{\mathrm{r}} H_{\mathrm{m} 2}{ }^{\ominus}-\Delta_{\mathrm{r}} H_{\mathrm{m} 1}{ }^{\ominus} \\
=(-455.57 \pm 0.24) \mathrm{kJ} \cdot \mathrm{mol}^{-1} \\
+\Delta_{\mathrm{r}} H_{\mathrm{m} 2}{ }^{\ominus}-\Delta_{\mathrm{r}} H_{\mathrm{m} 1}{ }^{\ominus} .
\end{gathered}
$$

According to (1) and the data in Table 2 to Table 4, the standard molar enthalpies of formation of the five kinds of 
TABLE 2: Thermochemical data of reactant system of sheet nano- $\mathrm{ZnO}$ with particle size of $45 \mathrm{~nm}$.

\begin{tabular}{lccccc}
\hline Reaction system & Number & $m_{\mathrm{ZnO}}(\mathrm{g})$ & $m_{\mathrm{KHSO}_{4}}(\mathrm{~g})$ & $Q_{1}(\mathrm{~mJ})$ & $\Delta_{\mathrm{r}} H_{\mathrm{ml}}{ }^{\ominus}\left(\mathrm{kJ} \cdot \mathrm{mol}^{-1}\right)$ \\
\hline & 1 & 0.0040 & 0.0134 & -1720.67 & -35.01 \\
$\mathrm{ZnO}+\mathrm{KHSO}_{4}+\mathrm{HCl}$ & 2 & 0.0040 & 0.0134 & -1734.42 & -35.29 \\
& 3 & 0.0040 & 0.0134 & -1739.00 & -35.38 \\
& 4 & 0.0040 & 0.0134 & -1766.67 & -35.94 \\
Average value & 5 & 0.0040 & 0.0134 & -1722.82 & -35.05 \\
\hline
\end{tabular}

TABLE 3: The $\Delta_{\mathrm{r}} H_{\mathrm{ml}}{ }^{\ominus}$ of reactants system of nano- $\mathrm{ZnO}$ with the morphology of sieve, block, column, and rod.

\begin{tabular}{lccccc}
\hline Reaction system & Number & Sieve $(45 \mathrm{~nm})$ & Block $(45 \mathrm{~nm})$ & Column $(37 \mathrm{~nm})$ & Rod $(36 \mathrm{~nm})$ \\
\hline & 1 & -35.69 & -36.05 & -29.66 & -31.45 \\
& 2 & -35.01 & -36.44 & -29.36 & -29.12 \\
$\mathrm{ZnO}+\mathrm{KHSO}_{4}+\mathrm{HCl}$ & 3 & -35.90 & -36.05 & -29.11 & -31.03 \\
$\Delta_{\mathrm{r}} H_{\mathrm{ml}}{ }^{\ominus}\left(\mathrm{kJ} \cdot \mathrm{mol}^{-1}\right)$ & 4 & -36.39 & -36.12 & -29.02 & -31.18 \\
& 5 & -35.52 & -36.74 & -29.17 & -31.70 \\
\hline Average value & 6 & -36.04 & -36.01 & $-29.24 \pm 0.24$ & $-31.37 \pm 0.26$ \\
$\Delta_{\mathrm{r}} H_{\mathrm{ml}}\left(\mathrm{kJ} \cdot \mathrm{mol}^{-1}\right)$ & & $-35.76 \pm 0.47$ & $-36.23 \pm 0.29$ & & \\
\hline
\end{tabular}

TABLE 4: Thermochemical data of system products.

\begin{tabular}{lccccc}
\hline Reaction system & Number & $m_{\mathrm{ZnSO}_{4} \cdot 7 \mathrm{H}_{2} \mathrm{O}}(\mathrm{g})$ & $m_{\mathrm{K}_{2} \mathrm{SO}_{4}}(\mathrm{~g})$ & $Q_{2}(\mathrm{~mJ})$ & $\Delta_{\mathrm{r}} H_{\mathrm{m} 2}{ }^{\ominus}\left(\mathrm{kJ} \cdot \mathrm{mol}^{-1}\right)$ \\
\hline & 1 & 0.0141 & 0.0086 & 4044.12 & 82.48 \\
& 2 & 0.0141 & 0.0086 & 4065.86 & 82.93 \\
$\mathrm{ZnSO}_{4} \cdot 7 \mathrm{H}_{2} \mathrm{O}+\mathrm{K}_{2} \mathrm{SO}_{4}+\mathrm{HCl}$ & 3 & 0.0141 & 0.0086 & 4060.14 & 82.81 \\
& 4 & 0.0141 & 0.0086 & 4068.27 & 82.98 \\
& 5 & 0.0141 & 0.0086 & 4064.98 & 82.91 \\
& 6 & 0.0141 & 0.0086 & 4046.63 & 82.53 \\
\hline Average value & & & & 4058.33 & $82.77 \pm 0.21$ \\
\hline
\end{tabular}

nano- $\mathrm{ZnO}$ with different morphologies were calculated as follows:

$$
\begin{aligned}
\Delta_{\mathrm{f}} H_{\mathrm{m}}{ }^{\ominus}(\mathrm{ZnO})= & (-455.57 \pm 0.24) \mathrm{kJ} \cdot \mathrm{mol}^{-1} \\
& +\Delta_{\mathrm{r}} H_{\mathrm{m} 2}{ }^{\ominus}-\Delta_{\mathrm{r}} H_{\mathrm{ml}}{ }^{\ominus} \\
= & (-455.57 \pm 0.24) \mathrm{kJ} \cdot \mathrm{mol}^{-1} \\
& +(88.77 \pm 0.21) \mathrm{kJ} \cdot \mathrm{mol}^{-1}-\Delta_{\mathrm{r}} H_{\mathrm{m} 1}{ }^{\ominus} \\
= & (-372.80 \pm 0.32) \mathrm{kJ} \cdot \mathrm{mol}^{-1}-\Delta_{\mathrm{r}} H_{\mathrm{ml}}{ }^{\Theta} \\
\Delta_{\mathrm{f}} H_{\mathrm{m}}{ }^{\ominus}(\text { Sheet })= & (-372.80 \pm 0.32) \mathrm{kJ} \cdot \mathrm{mol}^{-1} \\
& -(-35.37 \pm 0.34) \mathrm{kJ} \cdot \mathrm{mol}^{-1} \\
= & (-337.43 \pm 0.47) \mathrm{kJ} \cdot \mathrm{mol}^{-1} \\
\Delta_{\mathrm{f}} H_{\mathrm{m}}{ }^{\ominus}(\text { Block })= & (-372.80 \pm 0.32) \mathrm{kJ} \cdot \mathrm{mol}^{-1} \\
& -(-36.23 \pm 0.29) \mathrm{kJ} \cdot \mathrm{mol}^{-1}
\end{aligned}
$$

$$
\begin{aligned}
= & (-336.57 \pm 0.43) \mathrm{kJ} \cdot \mathrm{mol}^{-1} \\
\Delta_{\mathrm{f}} H_{\mathrm{m}}{ }^{\ominus}(\text { Sieve })= & (-372.80 \pm 0.32) \mathrm{kJ} \cdot \mathrm{mol}^{-1} \\
& -(-35.76 \pm 0.47) \mathrm{kJ} \cdot \mathrm{mol}^{-1} \\
= & (-337.04 \pm 0.57) \mathrm{kJ} \cdot \mathrm{mol}^{-1} \\
\Delta_{\mathrm{f}} H_{\mathrm{m}}{ }^{\ominus}(\text { Cloumn })= & (-372.80 \pm 0.32) \mathrm{kJ} \cdot \mathrm{mol}^{-1} \\
& -(-29.24 \pm 0.24) \mathrm{kJ} \cdot \mathrm{mol}^{-1} \\
= & (-343.56 \pm 0.39) \mathrm{kJ} \cdot \mathrm{mol}^{-1} \\
\Delta_{\mathrm{f}} H_{\mathrm{m}}{ }^{\ominus}(\mathrm{Rob})= & (-372.80 \pm 0.32) \mathrm{kJ} \cdot \mathrm{mol}^{-1} \\
& -(-31.37 \pm 0.26) \mathrm{kJ} \cdot \mathrm{mol}^{-1} \\
= & (-341.43 \pm 0.41) \mathrm{kJ} \cdot \mathrm{mol}^{-1} .
\end{aligned}
$$

3.3. Discussions. The experimental data show that the value of standard molar enthalpy of formation of nano- $\mathrm{ZnO}$ is 
larger than that of bulk $\mathrm{ZnO}\left[(-350.46 \pm 0.27) \mathrm{kJ} \cdot \mathrm{mol}^{-1}\right][17]$. The morphologies of the sheet, sieve, and block nanoparticles are similar to each other by the observation of SEM figure and their particle sizes are all $45 \mathrm{~nm}$. Their enthalpy values are $(-337.43 \pm 0.47) \mathrm{kJ} \cdot \mathrm{mol}^{-1}$ (sheet), $(-336.56 \pm 0.43) \mathrm{kJ} \cdot \mathrm{mol}^{-1}$ (block), and $(-337.04 \pm 0.57) \mathrm{kJ} \cdot \mathrm{mol}^{-1}$ (sieve), which are close to each other. So the influence of the morphology and particle size on the standard molar enthalpy of formation is smaller for the three particles. According to literature 17 and literature 18, the standard molar enthalpy of formation of the same morphology of nano- $\mathrm{ZnO}$ decreases with the increase of the particle size. The particle sizes of nano- $\mathrm{ZnO}$ with morphologies of column and rod are $37 \mathrm{~nm}$ and $36 \mathrm{~nm}$, which are smaller than the sheet, sieve, and block $(45 \mathrm{~nm})$ ones, so without considering the influence of the morphology of zinc oxide, the molar enthalpy values of nano- $\mathrm{ZnO}$ with morphology of column and rod should be bigger than the ones with morphologies of sheet, sieve, and block. But the experimental results are opposite $\left[\Delta_{\mathrm{f}} H_{\mathrm{m}}{ }^{\ominus}\right.$ (column) $=(-343.56 \pm$ $\left.0.39) \mathrm{kJ} \cdot \mathrm{mol}^{-1}, \Delta_{\mathrm{f}} H_{\mathrm{m}}{ }^{\Theta}(\mathrm{rod})=(-341.43 \pm 0.41) \mathrm{kJ} \cdot \mathrm{mol}^{-1}\right]$. The reason is that their particle sizes are smaller than the sheet, sieve, and block nano- $\mathrm{ZnO}$ particles; the surface area of the nanoparticles with morphologies of column and rod is bigger, so they are more instable than the other ones. The more instable the nano- $\mathrm{ZnO}$ is, the bigger the Gibbs free energy is. According to the thermodynamic formula, $\Delta_{\mathrm{f}} H_{\mathrm{m}}{ }^{\ominus}=\Delta_{\mathrm{f}} G_{\mathrm{m}}{ }^{\ominus}+T \Delta_{\mathrm{f}} S_{\mathrm{m}}{ }^{\ominus}$, the entropy of nano-ZnO must be considered. The irregularity of nano- $\mathrm{ZnO}$ with morphologies of column and rod is smaller, which determines its smaller entropy. So their entropy change $(\Delta S)$ becomes smaller in the generative process of nano- $\mathrm{ZnO}$. In conclusion, the standard molar enthalpy of formation is associated with Gibbs free energy and entropy $[18,19]$. This agrees well with the experimental results. According to the discussions above, it is concluded that the enthalpy values are influenced by the morphology and particle size. More experiments must be taken to obtain more influencing factors about the standard molar formation enthalpy of nano- $\mathrm{ZnO}$.

\section{Conflict of Interests}

The authors declare that there is no conflict of interests regarding the publication of this paper.

\section{Acknowledgment}

This project was sponsored by the Beijing Undergraduate Research Project (2014J00007).

\section{References}

[1] G. C. Fan, L. Sun, Z. Y. Huang, J. Y. Jiang, and Y. F. Li, “Thermodynamic functions of the grain-like $\mathrm{ZnO}$ nanostructures," Materials Letters, vol. 65, no. 17-18, pp. 2783-2785, 2011.

[2] Z. L. Wang, "ZnO nanowire and nanobelt platform for nanotechnology," Materials Science and Engineering R: Reports, vol. 64, no. 3-4, pp. 33-71, 2009.
[3] J. B. Tian, L. Liu, J. H. Qian, J. J. Xing, and J. L. Qin, "Research progress on preparing techniques and application of nano zinc oxide," Journal of Chemical Industry \& Engineering, vol. 2, pp. 46-49, 2008.

[4] C. Mejía-García, E. Díaz-Valdés, M. A. Ayala-Torres, J. RomeroIbarra, and M. López-López, "Influence of the hydrothermal method growth parameters on the zinc oxide nanowires deposited on several substrates," Journal of Nanomaterials, vol. 2014, Article ID 609262, 9 pages, 2014.

[5] Q. Xu, S. Zhou, and H. Schmidt, "Magnetic properties of $\mathrm{ZnO}$ nanopowders," Journal of Alloys and Compounds, vol. 487, no. 1-2, pp. 665-667, 2009.

[6] D. G. Gao, Z. Chen, and J. Z. Ma, "Progress in preparation and application of nano $\mathrm{ZnO}$ in textile industry," Printing, vol. 24, pp. 43-49, 2012.

[7] U. Pal and P. Santiago, "Controlling the morphology of $\mathrm{ZnO}$ nanostructures in a low-temperature hydrothermal process," The Journal of Physical Chemistry B, vol. 109, no. 32, pp. 1531715321, 2005.

[8] M.-P. Lu, J. Song, M.-Y. Lu et al., "Piezoelectric nanogenerator using p-type $\mathrm{ZnO}$ nanowire arrays," Nano Letters, vol. 9, no. 3, pp. 1223-1227, 2009.

[9] R. V. Chamberlin, "Mean-field cluster model for the critical behaviour of ferromagnets," Nature, vol. 408, no. 6810, pp. 337$339,2000$.

[10] T. Giebultowicz, "Breathing life into an old model," Nature, vol. 408, no. 6810, pp. 299-301, 2000.

[11] T. L. Hill, "Perspective: nanothermodynamics," Nano Letters, vol. 1, no. 3, pp. 111-112, 2001.

[12] T. L. Hill, "Extension of nanothermodynamics to include a onedimensional surface excess," Nano Letters, vol. 1, no. 3, pp. 159160, 2001.

[13] T. L. Hill, "A different approach to nanothermodynamics," Nano Letters, vol. 1, no. 5, pp. 273-275, 2001.

[14] G. Fan, Z. Huang, J. Chen, and Y. Ma, "Impact of size effects on the thermodynamic properties of zinc oxide micro/nano system," Acta Chimica Sinica, vol. 70, no. 7, pp. 938-942, 2012.

[15] X. M. Wu, J. X. Huang, H. Y. Li, and W. Li, "Standard enthalpies of formation of rare earth 1-proline chloride complexes [RE(1pro $\left.)_{2}\left(\mathrm{H}_{2} \mathrm{O}\right)_{5}\right]_{C_{3}}(\mathrm{RE}=\mathrm{Ho}, \mathrm{Er})$," Journal of Chemical and Engineering Data, vol. 56, no. 5, pp. 1991-1994, 2011.

[16] R. Rychlý and V. Pekárek, “The use of potassium chloride and tris(hydroxymethyl)aminomethane as standard substances for solution calorimetry," The Journal of Chemical Thermodynamics, vol. 9, no. 4, pp. 391-396, 1977.

[17] J. A. Dean, Lange's Handbook of Chemistry, McGraw-Hill, New York, NY, USA, 15th edition, 1998.

[18] B. Marongiu, A. Piras, S. Porcedda, and E. Tuveri, "Excess enthalpies of chloroalkylbenzene + alkylbenzene mixtures," Journal of Chemical and Engineering Data, vol. 52, no. 5, pp. 1941-1945, 2007.

[19] A. Gutterman, N. Rath, and J. Chickos, "Validation of the vaporization enthalpies of some simple aliphatic amides and their use in the evaluation of the vaporization enthalpy of valpromide and valnoctamide," Journal of Chemical and Engineering Data, vol. 58, no. 3, pp. 749-757, 2013. 

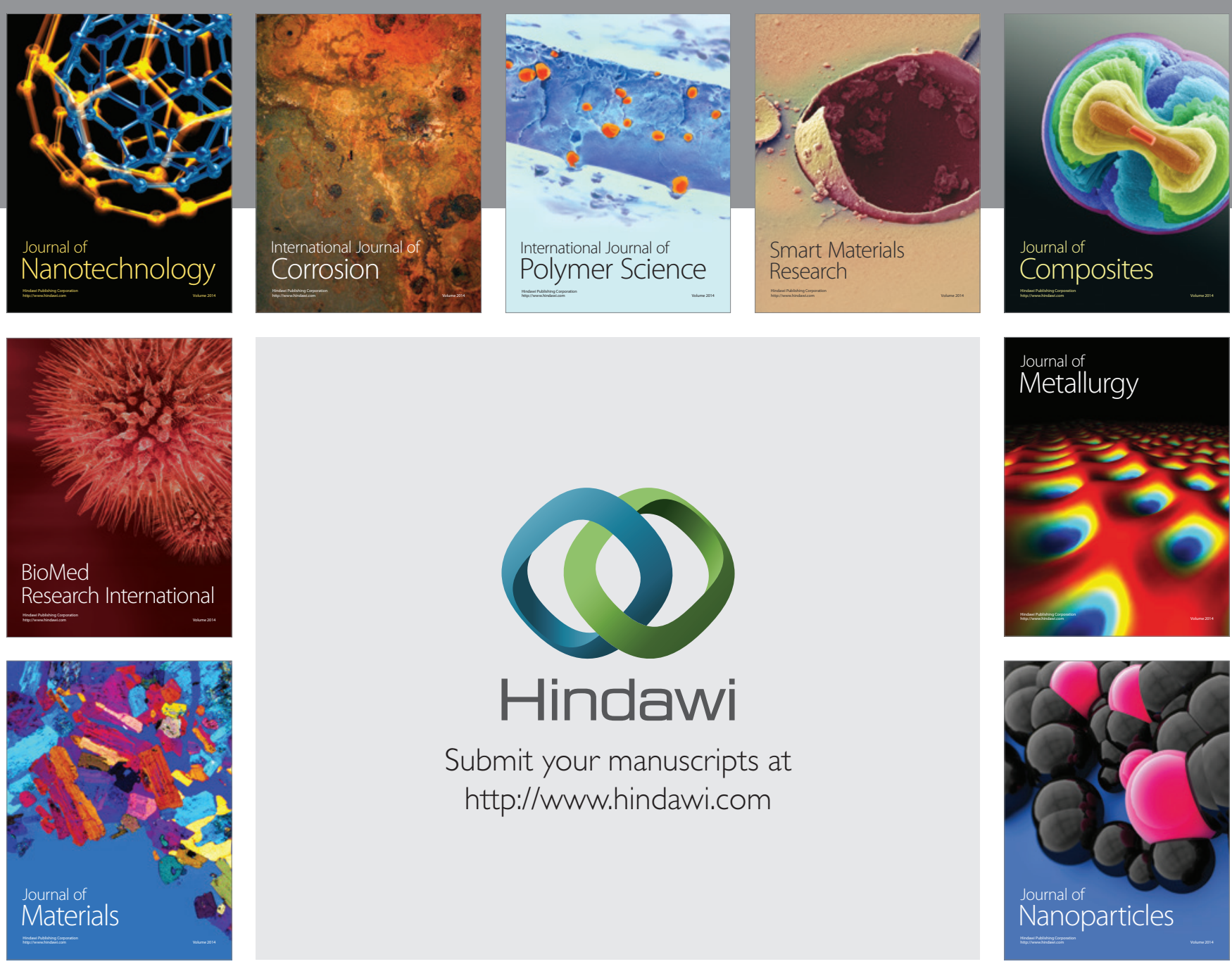

Submit your manuscripts at http://www.hindawi.com
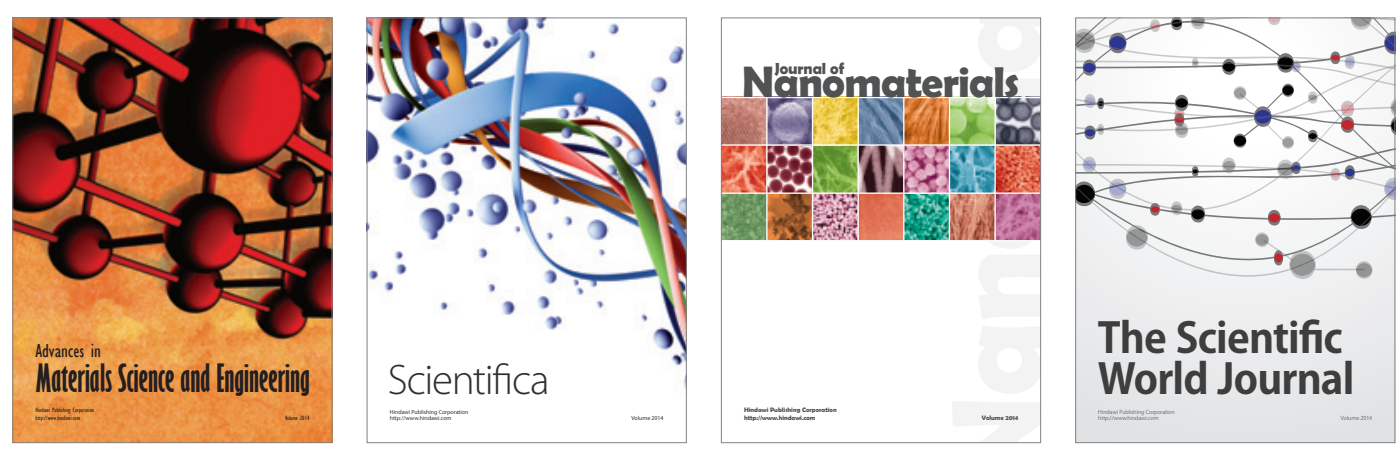

\section{The Scientific World Journal}
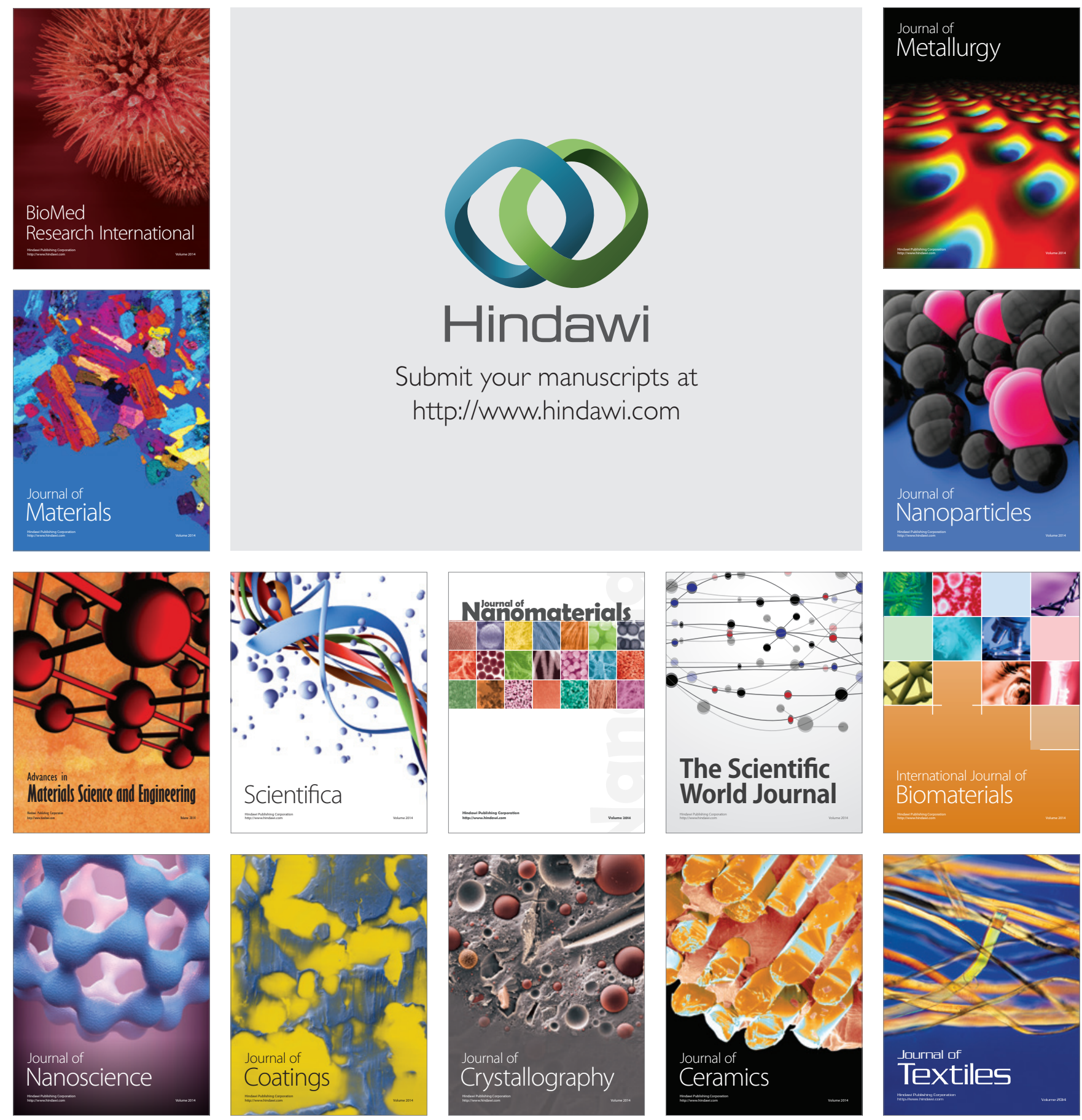